J. Appl. Numer. Optim. 2 (2020), No. 1, pp. 101-107

Available online at http://jano.biemdas.com

https://doi.org/10.23952/jano.2.2020.1.07

\title{
INEXACT ORBITS OF SET-VALUED NONEXPANSIVE MAPPINGS WITH SUMMABLE ERRORS
}

\author{
SIMEON REICH*, ALEXANDER J. ZASLAVSKI \\ Department of Mathematics, The Technion - Israel Institute of Technology, 32000 Haifa, Israel
}

\begin{abstract}
Given a set-valued nonexpansive mapping which acts on a metric space, we study the convergence of its inexact iterates to its attracting sets in the case where the errors are summable. In particular, we extend results which are known to hold for single-valued nonexpansive self-mappings of metric spaces.
\end{abstract}

Keywords. Attracting set; Inexact iteration; Metric space; Nonexpansive mapping.

\section{INTRODUCTION}

During more than fifty-five years now, there has been a lot of activity regarding the fixed point theory of nonexpansive (that is, 1-Lipschitz) mappings. See, for example, $[3,9,11,12,13,14$, $15,16,17,18,19,20,21,25,26]$ and references cited therein. This activity stems from Banach's classical theorem [1] regarding the existence of a unique fixed point for a strict contraction. It also concerns the convergence of (inexact) iterates of a nonexpansive mapping to one of its fixed points. Since that seminal result, many developments have taken place in this field including, in particular, studies of feasibility and common fixed point problems, which find important and diverse applications in the physical, engineering and medical sciences [8, 10, 22, 23, 24, 25, 26].

For example, in [5], it was shown that if every exact orbit of a nonexpansive mapping converges to one of its fixed points, then this convergence property also holds for its inexact orbits with summable errors. This result was obtained for a single-valued nonexpansive self-mapping of a complete metric space.

In this paper, we establish three variants of this result for inexact orbits of set-valued nonexpansive mappings with summable errors.

Such results have already found interesting applications. They are, for instance, an important ingredient in the study of superiorization and perturbation resilience of algorithms. See [2, $4,6,7]$ and references mentioned therein. The superiorization methodology works by taking an iterative algorithm, investigating its perturbation resilience, and then using proactively such perturbations in order to "force" the perturbed algorithm to do, in addition to its original task, something useful.

This methodology can be explained by the following result on convergence of inexact iterates.

${ }^{*}$ Corresponding author.

E-mail addresses: sreich@technion.ac.il (S. Reich), ajzasl@technion.ac.il (A.J. Zaslavski).

Received August 14, 2019; Accepted December 15, 2019.

(C)2020 Journal of Applied and Numerical Optimization 
Assume that $(X,\|\cdot\|)$ is a Banach space, the mapping $A: X \rightarrow X$ is nonexpansive, and that for each $x \in X$, the sequence $\left\{A^{n} x\right\}_{n=1}^{\infty}$ converges in the norm topology. Assume further that the point $x_{0}$ belongs to $X,\left\{\beta_{k}\right\}_{k=0}^{\infty}$ is a sequence of positive numbers satisfying

$$
\sum_{k=0}^{\infty} \beta_{k}<\infty
$$

$\left\{v_{k}\right\}_{k=0}^{\infty} \subset X$ is a norm bounded sequence and for each integer $k \geq 0$,

$$
x_{k+1}=A\left(x_{k}+\beta_{k} v_{k}\right) \text {. }
$$

Then it was shown in [5] that the sequence $\left\{x_{k}\right\}_{k=0}^{\infty}$ converges in the norm topology of $X$ and its limit is a fixed point of $A$. In this case the mapping $A$ is said to be bounded perturbation resilient (see [6]). In other words, if all the exact iterates of a nonexpansive mapping converge, then its inexact iterates with bounded summable perturbations converge too.

Now assume that the point $x_{0} \in X$ and the sequence $\left\{\beta_{k}\right\}_{k=0}^{\infty}$ satisfying (1.1) are given, and that we need to find an (approximate) fixed point of $A$. In order to meet this goal, we construct a sequence $\left\{x_{k}\right\}_{k=1}^{\infty}$ defined by (1.2). Under an appropriate choice of the norm bounded sequence $\left\{v_{k}\right\}_{k=0}^{\infty}$, the sequence $\left\{x_{k}\right\}_{k=1}^{\infty}$ also possesses some useful property. For example, the sequence $\left\{f\left(x_{k}\right)\right\}_{k=1}^{\infty}$ can be decreasing, where $f$ is a given function.

We remark in passing that the convergence of perturbed iterates of set-valued mappings was also studied in [20].

Let $(X, \rho)$ be a metric space. For each $x \in X$ and each $r>0$, set

$$
B(x, r):=\{y \in X: \rho(x, y) \leq r\} .
$$

For each $x \in X$ and each nonempty set $A \subset X$, define

$$
\rho(x, A):=\inf \{\rho(x, y): y \in A\} .
$$

Finally, for each pair of nonempty sets $A, B \subset X$, define

$$
H(A, B):=\max \left\{\sup _{x \in A} \rho(x, B), \sup _{y \in B} \rho(x, A)\right\} .
$$

Assume that a mapping $T: X \rightarrow 2^{X} \backslash\{\emptyset\}$ is such that $T(x)$ is closed for each $x \in X$, for each $x, y \in X$, we have

$$
H(T x, T y) \leq \rho(x, y)
$$

and that $F \subset X$ is a nonempty closed set.

In this paper, we obtain three results (see Theorems 2.1, 3.1 and 4.1 below). They are stated and proved in Sections 2, 3 and 4, respectively.

\section{THE FIRST RESULT}

Theorem 2.1. Assume that the following property holds:

(a) for each sequence $\left\{x_{i}\right\}_{i=0}^{\infty} \subset X$ such that

$$
x_{i+1} \in T\left(x_{i}\right), i=0,1, \ldots,
$$

the relation

$$
\lim _{i \rightarrow \infty} \rho\left(x_{i}, F\right)=0
$$

is true. 
Let $\left\{\gamma_{i}\right\}_{i=1}^{\infty} \subset(0, \infty)$ satisfy

$$
\sum_{i=1}^{\infty} \gamma_{i}<\infty
$$

and let $\left\{x_{i}\right\}_{i=0}^{\infty} \subset X$ satisfy, for each integer $i \geq 0$,

$$
\rho\left(x_{i+1}, T x_{i}\right) \leq \gamma_{i+1} \text {. }
$$

Then

$$
\lim _{i \rightarrow \infty} \rho\left(x_{i}, F\right)=0 .
$$

Proof. Let $\varepsilon>0$. Choose a natural number $n_{0}$ such that

$$
\sum_{i=n_{0}}^{\infty} \gamma_{i}<\varepsilon / 6
$$

Set

$$
y_{n_{0}}=x_{n_{0}} .
$$

Assume that $n \geq n_{0}$ is an integer, that a finite sequence $\left\{y_{i}\right\}_{i=n_{0}}^{n} \subset X$ has already been defined and that for each natural number $i$ satisfying $n_{0}<i \leq n$, we have

$$
\rho\left(x_{i}, y_{i}\right) \leq 3 \sum_{j=n_{0}+1}^{i} \gamma_{j}
$$

We now proceed to define $y_{n+1} \in X$. In view of (1.1), we have

$$
H\left(T x_{n}, T y_{n}\right) \leq \rho\left(x_{n}, y_{n}\right) .
$$

From (2.1), we see that there exists a point

$$
z \in T x_{n}
$$

such that

$$
\rho\left(x_{n+1}, z\right) \leq 2 \gamma_{n+1} .
$$

It follows from (2.3) and (2.4) that

$$
\rho\left(z, T y_{n}\right) \leq \rho\left(x_{n}, y_{n}\right) .
$$

Hence, there exists a point

$$
y_{n+1} \in T y_{n}
$$

such that

$$
\rho\left(z, y_{n+1}\right) \leq \rho\left(x_{n}, y_{n}\right)+\gamma_{n+1} .
$$

In view of (2.5) and (2.6), we have

$$
\begin{aligned}
\rho\left(x_{n+1}, y_{n+1}\right) & \leq \rho\left(x_{n+1}, z\right)+\rho\left(z, y_{n+1}\right) \\
& \leq 2 \gamma_{n+1}+\rho\left(x_{n}, y_{n}\right)+\gamma_{n+1}
\end{aligned}
$$

and

$$
\rho\left(x_{n+1}, y_{n+1}\right) \leq \rho\left(x_{n}, y_{n}\right)+3 \gamma_{n+1} \text {. }
$$


From (2.2), we see that the assumption made for $n$ also holds for $n+1$. Thus we have constructed by induction a sequence $\left\{y_{i}\right\}_{i=n_{0}}^{\infty}$ such that (2.2) holds for all integers $i>n_{0}$. It follows from (2.2) that, for all integers $k \geq n_{0}$,

$$
\rho\left(x_{k}, y_{k}\right) \leq 3 \sum_{i=n_{0}}^{k} \gamma_{i}<\varepsilon / 2 \text {. }
$$

and

$$
y_{k+1} \in T y_{k}
$$

Property (a) implies that

$$
\lim _{i \rightarrow \infty} \rho\left(y_{i}, F\right)=0 \text {. }
$$

In view of (2.7) and (2.8), we have, for all sufficiently large natural numbers $k$,

$$
\rho\left(x_{k}, F\right)<\varepsilon / 2 .
$$

Since $\varepsilon$ is an arbitrary positive number, we conclude that

$$
\lim _{k \rightarrow \infty} \rho\left(x_{k}, F\right)=0 \text {. }
$$

This completes the proof of Theorem 2.1.

\section{THE SECOND RESULT}

Theorem 3.1. Assume that the following property holds:

(b) for each sequence $\left\{x_{i}\right\}_{i=0}^{\infty} \subset X$ such that

$$
x_{i+1} \in T\left(x_{i}\right), i=0,1, \ldots,
$$

the relation

$$
\liminf _{i \rightarrow \infty} \rho\left(x_{i}, F\right)=0
$$

is true.

$$
\text { Let }\left\{\gamma_{i}\right\}_{i=1}^{\infty} \subset(0, \infty) \text { satisfy }
$$

$$
\sum_{i=i}^{\infty} \gamma_{i}<\infty
$$

and let $\left\{x_{i}\right\}_{i=0}^{\infty} \subset X$ satisfy, for each integer $i \geq 0$,

$$
\rho\left(x_{i+1}, T x_{i}\right) \leq \gamma_{i+1} .
$$

Then

$$
\liminf _{i \rightarrow \infty} \rho\left(x_{i}, F\right)=0 .
$$

Proof. Let $\varepsilon>0$. Choose a natural number $n_{0}$ such that

$$
\sum_{i=n_{0}}^{\infty} \gamma_{i}<\varepsilon / 6
$$

Arguing as in the proof of Theorem 2.1, we construct a sequence $\left\{y_{i}\right\}_{i=n_{0}}^{\infty} \subset X$ such that

$$
\begin{gathered}
y_{n_{0}}=x_{n_{0}}, \\
y_{i+1} \in T\left(y_{i}\right) \text { for all integer } i \geq n_{0}
\end{gathered}
$$


and

$$
\rho\left(x_{i}, y_{i}\right) \leq \varepsilon \text { for all integer } i \geq n_{0} .
$$

Property (b) and (3.1) imply that

$$
\liminf _{i \rightarrow \infty} \rho\left(y_{i}, F\right)=0 .
$$

In view of (3.2) and (3.3), we have

$$
\liminf _{i \rightarrow \infty} \rho\left(x_{i}, F\right) \leq \varepsilon .
$$

Since $\varepsilon$ is an arbitrary positive number, we conclude that

$$
\liminf _{k \rightarrow \infty} \rho\left(x_{k}, F\right)=0 .
$$

Theorem 2.1 is proved.

\section{THE THIRD RESULT}

For every set $A$, we denote by $\operatorname{Card}(A)$ its cardinality.

Theorem 4.1. Assume that the following property holds:

(c) for each sequence $\left\{z_{i}\right\}_{i=0}^{\infty} \subset X$ such that

$$
z_{i+1} \in T\left(z_{i}\right), i=0,1, \ldots,
$$

and each $\varepsilon>0$, we have

$$
\lim _{n \rightarrow \infty} \operatorname{Card}\left(\left\{i \in\{0, \ldots, n-1\}: \rho\left(z_{i}, F\right)>\varepsilon\right\}\right) n^{-1}=0 .
$$

Let $\left\{\gamma_{i}\right\}_{i=1}^{\infty} \subset(0, \infty)$ satisfy

$$
\sum_{i=i}^{\infty} \gamma_{i}<\infty
$$

and let $\left\{x_{i}\right\}_{i=0}^{\infty} \subset X$ satisfy for each integer $i \geq 0$,

$$
x_{i+1} \in T\left(x_{i}\right)
$$

and

Then, for each $\varepsilon>0$,

$$
\rho\left(x_{i+1}, T x_{i}\right) \leq \gamma_{i+1}
$$

$$
\lim _{n \rightarrow \infty} \operatorname{Card}\left(\left\{i \in\{0, \ldots, n-1\}: \rho\left(x_{i}, F\right)>\varepsilon\right\}\right) n^{-1}=0 .
$$

Proof. Let $\varepsilon>0$. Choose a natural number $n_{0}$ such that

$$
\sum_{i=n_{0}}^{\infty} \gamma_{i}<\varepsilon / 6
$$

Arguing as in the proof of Theorem 2.1, we construct a sequence $\left\{y_{i}\right\}_{i=n_{0}}^{\infty} \subset X$ such that

$$
\begin{gathered}
y_{n_{0}}=x_{n_{0}}, \\
y_{i+1} \in T\left(y_{i}\right) \text { for all integer } i \geq n_{0}
\end{gathered}
$$

and

$$
\rho\left(x_{i}, y_{i}\right) \leq \varepsilon / 2 \text { for all integer } i \geq n_{0}
$$


Property (c) and (4.1) imply that

$$
\lim _{k \rightarrow \infty} \operatorname{Card}\left(\left\{i \in\left\{n_{0}, \ldots, k-1\right\}: \rho\left(y_{i}, F\right)>\varepsilon / 2\right\}\right) k^{-1}=0 .
$$

Let $n>n_{0}$ be an integer. By (4.2) and (4.3), we have

$$
\begin{aligned}
& \left\{i \in\left\{n_{0}, \ldots, n-1\right\}: \rho\left(x_{i}, F\right)>\varepsilon\right\} \\
& \subset\left\{i \in\left\{n_{0}, \ldots, n-1\right\}: \rho\left(y_{i}, F\right)>\varepsilon / 2\right\}
\end{aligned}
$$

and

$$
\begin{aligned}
& n^{-1} \operatorname{Card}\left(\left\{i \in\{0, \ldots, n-1\}: \rho\left(x_{i}, F\right)>\varepsilon\right\}\right) \\
& \leq n^{-1}\left(n_{0}+\operatorname{Card}\left(\left\{i \in\left\{n_{0}, \ldots, n-1\right\}: \rho\left(y_{i}, F\right)>\varepsilon / 2\right\}\right)\right. \\
& \rightarrow 0
\end{aligned}
$$

as $n \rightarrow \infty$. This completes the proof of Theorem 4.1.

Remark 4.1. It is not difficult to see that the above result remains true if we replace the $n^{-1}$ factor by $t_{n}^{-1}$, where $\left\{t_{n}\right\}_{n=1}^{\infty}$ is any strictly increasing sequence of natural numbers.

\section{Acknowledgements}

The first author was partially supported by the Israel Science Foundation (Grant No. 820/17), by the Fund for the Promotion of Research at the Technion and by the Technion General Research Fund. Both authors thank the three referees for their helpful comments and suggestions.

\section{REFERENCES}

[1] S. Banach, Sur les opérations dans les ensembles abstraits et leur application aux équations intégrales, Fund. Math. 3 (1922), 133-181.

[2] H. H. Bauschke, V. R. Koch, Projection methods: Swiss army knives for solving feasibility and best approximation problems with half-spaces, Contemporary Math. 636 (2015), 1-40.

[3] A. Betiuk-Pilarska, T. Domínguez Benavides, Fixed points for nonexpansive mappings and generalized nonexpansive mappings on Banach lattices, Pure Appl. Func. Anal. 1 (2016), 343-359.

[4] D. Butnariu, R. Davidi, G. T. Herman, I. G. Kazantsev, Stable convergence behavior under summable perturbations of a class of projection methods for convex feasibility and optimization problems, IEEE J. Sel. Topics Signal Processing 1 (2007), 540-547.

[5] D. Butnariu, S. Reich, A. J. Zaslavski, Convergence to fixed points of inexact orbits of Bregman-monotone and of nonexpansive operators in Banach spaces, Fixed Point Theory and its Applications, pp. 11-32, Yokohama Publishers, Yokohama, 2006

[6] Y. Censor, R. Davidi, G. T. Herman, Perturbation resilience and superiorization of iterative algorithms, Inverse Probl. 26 (2010), 065008.

[7] Y. Censor, R. Davidi, G. T. Herman, R. W. Schulte, L. Tetruashvili, Projected subgradient minimization versus superiorization, J. Optim. Theory Appl. 160 (2014), 730-747.

[8] Y. Censor, M. Zaknoon, Algorithms and convergence results of projection methods for inconsistent feasibility problems: a review, Pure Appl. Func. Anal. 3 (2018), 565-586.

[9] F. S. de Blasi, J. Myjak, S. Reich, A. J. Zaslavski, Generic existence and approximation of fixed points for nonexpansive set-valued maps, Set-Valued Var. Anal. 17 (2009) , 97-112.

[10] A. Gibali, A new split inverse problem and an application to least intensity feasible solutions, Pure Appl. Funct. Anal. 2 (2017), 243-258.

[11] K. Goebel, W. A. Kirk, Topics in Metric Fixed Point Theory, Cambridge University Press, Cambridge, 1990.

[12] K. Goebel, S. Reich, Uniform Convexity, Hyperbolic Geometry, and Nonexpansive Mappings, Marcel Dekker, New York and Basel, 1984. 
[13] W. A. Kirk, Contraction Mappings and Extensions, Handbook of Metric Fixed Point Theory, pp. 1-34, Kluwer, Dordrecht, 2001.

[14] R. Kubota, W. Takahashi, Y. Takeuchi, Extensions of Browder's demiclosedness principle and Reich's lemma and their applications, Pure Appl. Func. Anal. 1 (2016), 63-84.

[15] E. Pustylnyk, S. Reich, A. J. Zaslavski, Convergence to compact sets of inexact orbits of nonexpansive mappings in Banach and metric spaces, Fixed Point Theory Appl. 2008 (2008), 1-10.

[16] X. Qin, J.-C. Yao, Projection splitting algorithms for nonself operators, J. Nonlinear Convex Anal. 18 (2017), 925-935.

[17] S. Reich, A. J. Zaslavski, Well-posedness of fixed point problems, Far East J. Math. Sci. Special Volume (Functional Analysis and Its Applications), Part III (2001), 393-401.

[18] S. Reich, A. J. Zaslavski, Generic Aspects of Metric Fixed Point Theory, Handbook of Metric Fixed Point Theory, PP. 557-575, Kluwer, Dordrecht, 2001.

[19] S. Reich, A. J. Zaslavski, Convergence to attractors under perturbations, Commun. Math. Anal. 10 (2011), 57-63.

[20] S. Reich, A. J. Zaslavski, Convergence of perturbed iterates of set-valued mappings, J. Fixed Point Theory Appl. 10 (2011), 181-190.

[21] S. Reich, A. J. Zaslavski, Genericity in Nonlinear Analysis, Developments in Mathematics, vol. 34, Springer, New York, 2014.

[22] S. Reich, A. J. Zaslavski, Asymptotic behavior of inexact infinite products of nonexpansive mappings in metric spaces, Z. Anal. Andwend. 33 (2014), 101-117.

[23] W. Takahashi, The split common fixed point problem and the shrinking projection method for new nonlinear mappings in two Banach spaces, Pure Appl. Funct. Anal. 2 (2017), 685-699.

[24] W. Takahashi, A general iterative method for split common fixed point problems in Hilbert spaces and applications, Pure Appl. Funct. Anal. 3 (2018), 349-369.

[25] A. J. Zaslavski, Approximate solutions of common fixed point problems, Springer Optimization and Its Applications, Springer, Cham, 2016.

[26] A. J. Zaslavski, Algorithms for solving common fixed point problems, Springer Optimization and Its Applications, Springer, Cham, 2018. 